\title{
Investigating Patterns of Mathematics Talk in a Rural South African Classroom of an Early Career Primary School Teacher
}

\section{Benjamin Shongwe ORCID iD: https://orcid.org/0000-0001-8083-6462}

\begin{abstract}
This interpretivist research is designed to report on an investigation whose purpose is to explore the case of the patterns of talk through which an early career mathematics teacher and her learners interact to construct mathematical knowledge in a South African rural school. Despite increased interest in classroom interactions in primary mathematics across all grades, the problem is that little research has focused on measuring the level of communication patterns taking place in mathematics classes of early career teachers. Exploring the level of communication patterns in mathematics classrooms entails exploration of conjecturing given that conjecturing is fundamental to learning mathematics. To characterise classroom communication patterns, classroom interactions in three lessons $(n=48)$ of a conveniently selected early career teacher were observed. In framing this study, I draw on various aspects of Vygotsky's sociocultural theory (SCT). To corroborate data obtained from these observations, the RTOP was adopted to detect the degree to which the early career teacher's classroom instruction was reformed. The findings indicate that approximately two thirds of the communication patterns were authoritative and therefore low in the level of interanimation of learners' conjectures. Recommendation for future research is for studies that incorporate both rural and urban schools so that broader understandings of findings can be gained to better understand the problem prior to designing intervention programmes. The implication of these findings for teacher education programmes
\end{abstract}


is that there is a need to foster instructional practices that encourage the delivery of mathematics that is honest to mathematics as a discipline and honours mathematics learners. From a gender equity position, and in light of a plethora of intervention efforts particularly targeting female learners, future research could shed light on how participation and the quality of classroom talk are distributed across gender.

Keywords: Early career teacher, rural school, communication patterns, sociocultural theory, mathematics education reform

\section{Introduction}

Classroom talk has been studied over many years and an extensive literature reports on the challenges experienced teachers face in promoting reform initiatives advocated by mathematics education bodies (Common Core State Standards Initiative [CCSSI] 2010; Department of Basic Education [DBE] 2011; National Council of Teachers of Mathematics [NCTM] 2000) and researchers (Aaron \& Herbst 2015; Bergqvist 2005; Chinnappan 2005; Jones \& Fujita 2013; Manouchehri \& St. John 2006) in the teaching and learning of mathematics. By classroom talk is meant here the 'ways of representing, thinking, talking, and agreeing and disagreeing that teachers and students use to engage in [mathematical] tasks' (National Council of Teachers of Mathematics [NCTM] 1991: 34). According to the Curriculum and Assessment Policy Statement (CAPS) (Department of Basic Education [DBE] 2011: 217), teachers are mandated to stimulate learners' natural curiosity and reasoning when making conjecturing to solve mathematical problems akin to adult experts. The CAPS is one of the policy instruments - the one prominent other being instructional materials such as prescribing textbooks to be used in the classroom - South African education system's framework mobilised to effect reform in the classrooms.

For the purpose of this study, an early career teacher is defined as a beginning teacher in their first five years of teaching (Schuck, Aubusson, Buchanan, Varadharajan \& Burke 2018; Raue \& Gray 2015). Linked to this interest is the notion that learners are capable of making insightful conjectures (e.g., Balacheff 1988; Lee \& Sriraman 2011; Mueller \& Maher 2009). In addition, despite increased interest in classroom interactions in primary mathematics across all grades, the problem is that little research has focused 
on measuring the level of communication patterns taking place in mathematics classrooms of early career teachers. Cañadas, Deulofeu, Figueiras, Reid, and Yevdokimov (2007), building on the work of Yevdokimov (2003), define a mathematical 'problem' as a task with two defining characteristics: (1) no solution is immediately available to the learner, that is, the task is not a trivial exercise, practicing a skill learnt previously; and (2) it is possible for the learner to find a solution provided their prior knowledge is adequate. The term 'problem' in the context of mathematics is used here as understood by Callejo and Vila (2009: 112) to designate a mathematical question whose solution is not immediately accessible to the solver, because they do not have an algorithm for relating the data with the conclusion. Thus, the option available to these learners is to formulate guesses or more precisely, to make conjectures.

The Standards for Mathematical Practice (Common Core State Standards Initiative [CCSSI] 2010) implores teachers to seek to create opportunities for learners to make conjectures for consideration by classmates and build a logical progression of statements to explore the truth of their conjectures. These mandates are important to advance because if learners are not given an opportunity to see mathematics through the perspective of a mathematician they can be left with a false impression of the nature of mathematics (Rumsey 2012).

Studies and curriculum documents emphasise the importance of making conjectures not only to reflect knowledge construction in the mathematics discipline but also to respect learners of mathematics. For instance, Lampert (1990) argues that to change meaning of learning, conjectures must be a feature of classroom interactions to help learners understand the mathematical structures underlying solutions to mathematical problems even at primary school level. Similarly, Rumsey (2013) points out that conjecturing is one of the elements of doing mathematics. Thus, mathematics education documents and researchers advocate for a focus on conjecturing in mathematics across all grades (Jones \& Fujita 2013) as the basis of constructing and communicating mathematical knowledge in ways that 'reflect fidelity to the discipline of mathematics' (Aaron \& Herbst 2015: 1). Traditional classrooms are dominated by teacher talk that entails lecturing, drilling, and quizzing. Although these are useful instructional tools, they are unlikely to reveal misconceptions in context - even from what on the surface seems like a 'correct' answer - thus inhibiting the teacher from chiming in by adjusting their teaching. 
However, these studies have focused on experienced teachers and little is known about the various patterns of communication obtaining in classrooms of early career teachers. The purpose of this study is to address this gap in literature by not only shedding light on the communication approach in mathematics classroom interactions of an early career teacher but also the quality of these interactions. Thus, the main research question posed in this paper is: What is the nature of the communication approach in the classroom of an early career teacher? The study was guided by Vygotsky's (1978) sociocultural theory of learning, which is premised on the notion that individual learning understood by studying how the classroom environment is organised and how learners participate in social practices.

As a consequence, the next section considers literature primarily on conjecturing. Through the lens of the sociocultural conceptual framework, this article describes the classroom talk obtaining in the classroom of an early career mathematics teacher in the midst of a curriculum that foregrounds conjecturing. The conclusion highlights the lessons that can be drawn from both the findings in this study and the literature to make recommendations to support meaning making in the classrooms of teachers who are in the early years of their career.

\section{The Review of Literature}

In this section I situate the study in terms of previous work on conjecturing. It is believed here that conjecturing can contribute the arrest of the declining enrolments in mathematics across various countries in the world. Thus, attempts to foster conjecturing in mathematics not only help to reflect the character of the mathematics discipline, but they also should contribute towards addressing the decline in learner participation in mathematics. The literature reviewed in this section is premised on the intellectual-honesty principle which advocates for the teaching and learning of mathematics that is honest to mathematics as a discipline and honours mathematics learners. Very few will contest the statement that the best way to honour the mathematics discipline in the classroom is to foster conjecturing. In addition, the mathematics classroom is a learning site 'in which the children are expected to publicly express their thinking, and engage in mathematical practice characterized by conjecture, argument, and justification' (Cobb, Wood \& Yackel 1993: 28). 


\section{The Decline in Mathematics Interest}

Learner participation in mathematics is steadily declining in many countries (Organisation for Economic Cooperation and Development [OECD] 2006). South Africa is no exception to the rule. The proportion of learners enrolled for mathematical literacy rather than mathematics is skewed in favour of the former. For instance, Umalusi (2014) reports which indicate a 17\% decline in the number of learners who wrote mathematics between 2009 and 2013 (from about 290400 to 241400 ). At the same time, the number of candidates writing mathematics literacy rose sharply to $58 \%$ of the 2013 cohort. Various reasons are attributed to the decline.

The hypothesis in this study is that one of the origins of this decline is the distorted nature of mathematics presented in primary school classrooms through to high school. This article will focus on the talk during an early career teacher's actual classroom practice while keeping an eye on the discipline of mathematics because talk is thought to be a primary medium through which learning and teaching takes place (Ball, Lewis \& Thames 2008). Teaching through dialogic interactions is a critical lesson for teachers to learn (MacIsaac $\&$ Falconer 2002). It is accepted that mathematics classrooms are dominated by discussions which follow transmission methods of teaching of the InitiationResponse-Evaluation (IRE) format. The IRE pattern of instructional practice also referred to as the 'triadic dialogue' (Mehan 1979) - takes place where the teacher initiates the question, the learner responds and finally the teacher evaluates the response in terms of school mathematics view. This links with Manouchehri an St. John's (2006) argument that classroom environments in which opportunities for learners to share ideas which lead to an increase in learners' confidence to make conjectures are rare. The CAPS document advocates for the making of conjectures because of their power to foster productive construction of mathematics by learners for themselves.

Research in classroom practices of mathematics teaching and learning has also underscored the centrality of communication of mathematical knowledge in the learning of mathematics. In an effort to understand what distinguishes higher performing schools from average performing schools, the National Center for Educational Achievement (National Center for Educational Achievement [NCEA] 2009: 24) found that the former embrace instructional practices that foster classroom environments where learners 'feel safe trying to answer questions, make presentations, and do experiments, even 


\section{Benjamin Shongwe}

if they make a mistake'. Therefore, it is the teachers' responsibility to treat learners' ideas as conjectures. According to Chinnappan (2005), making conjectures and proving them creates classroom practice that could provide rich learning contexts that foster learners' independent exploration of problems. Thus, conjectures are the basis for proving (Reid, Understanding Proof and Transforming Teaching 2011). In this study, a conjecture is viewed as a problem because its proof is not readily available to learners.

\section{Conjecturing}

The importance of conjecturing in the construction of mathematical knowledge has been emphasised in mathematics education research throughout the grades (Chinnappan 2005; Komatsu 2010; Protheroe 2007) and different national mathematics standards (Department of Basic Education [DBE] 2011; Common Core State Standards Initiative [CCSSI] 2010; National Council of Teachers of Mathematics [NCTM] 2000). I draw on the work of, Cañadas, Deulofeu, Figueiras, Reid, and Yevdokimov (2007) who characterise five exhaustive types of conjecturing familiar in mathematics education research: empirical induction from a finite number of discrete cases and from dynamic cases, analogy, abduction and perceptually based conjecturing. In the next section I describe each in turn. In describing the instructional norms that underpin classroom interactions between the teacher and learners, Aaron and Herbst (2015) point out that once the conjecture has been discussed, the class moves on to discussing another conjecture or to the proof of an endorsed conjecture.

Worth noting is that conjecturing entails engaging in classroom interactions in which learners' ideas invite justifications, counterexamples, and therefore refinement from interlocutors who draw on concepts from a range of observations and previously learnt mathematical ideas. Thus, conjecturing fosters classroom interactions in which mathematical authority and ownership shift from the textbook or teacher to the community of learners who become producers of mathematical knowledge (Bay-Williams, McGatha, Kobett \& Wray 2013; Rumsey \& Langrall Promoting Mathematical Argumentation 2016). Drawing on the work of Jones and Fujita (2013), the practice of making conjectures unfold in classrooms in two distinct phases: (1) learners working privately (individually or in groups) making conjectures and (2) the class publicly discusses those conjectures. In this study, I am interested in exploring the latter phase because it is broader in the sense that not only does it capture 
learners' ideas but also the teacher as he or she introduces learners to the social knowledge of mathematics. That is, in Mortimer and Scott's (2003: 17) terms, the second phase involves interactions as a 'public performance. This performance takes place on the 'social plane', a term Vygotsky (1978) coined when describing classroom interactions in which a teacher works with a class of learners in a school. Ideas in social situations are rehearsed using a range of communication modes: talk, listening, gesture, writing, visual images, and actions. In this study, the focus is limited to the orchestration of classroom talk involving both teacher and her learners geared towards learning mathematics. The focus on talk is not intended to undermine the importance of other forms of communication, which are also contributory to the learning process (Abrahamson \& Sánchez-García 2016; Schultz 2009).

The concept of conjecturing is important to consider in the teaching and learning of mathematics because it reveals the various activities in which mathematicians engage prior to reaching the final form of a proof (Komatsu 2010). Thurston (1995) views mathematical practice as an intellectually gratifying human activity that requires social interaction and conjecturing. That said, it is important to note that the mathematics teacher is central to this process in the sense that they have the responsibility not only to introduce learners to the social knowledge of mathematics but also to encourage learners to verbalise their thoughts and building on one another's ideas while critiquing the ideas of others and asking probing questions that require them to refine their ideas. Classroom talk does not only help the teacher to evaluate learners' mathematical understanding, but also to evaluate learners' mathematical communication features (vocabulary, symbolic representations, syntax, semantics, and linguistic features).

\section{Previous Studies on Conjecturing}

My contention here is informed by Vygotsky's perspective that a child's learning is not dependent on their maturity but rather on them being supported by a 'more knowledgeable other'. In support of my argument, is a particularly significant and recent study conducted by Rumsey and Langrall (2016). In one task, Grade 4 learners were presented with a false claim on the basis of a subset of numbers, 'Every time you multiply two numbers, you are always going to get an even number as the product'. They found that that learners in the primary grades are able to make observations of patterns and conjecture about mathe- 
matical ideas.

Reid (2002) conducted a study in which he wanted to illustrate a particular pattern of learners' conjecturing in a mathematical activity occurring in a Grade 5 classroom of a teacher-researcher in an ethnically, religiously, and linguistically diverse private school. The activity involved presenting learners with a $5 \times 5$ grid for which they had to find and prove that they had found all the squares. Her learners reasoned as the number of grids contained increasing squares and made conjectures with a view to finding their proofs. He found that his learners were able to observe patterns which enabled them not only to make conjectures but also to test them.

Komatsu (2010) investigated learners' mathematical activities with counter-examples in a Grade 5 mathematics classroom of a public primary school in Japan. He interviewed these learners on a task related to conjecturing so as to investigate that 'the sums of two-digit integers and the integers whose digits are the reverse of the order of the original integers' digits', for example:

$$
32+23=55
$$

The learners were able to make various conjectures and attempted to prove them.

\section{The Quality of Communication}

Although communicating mathematical knowledge is seen by mathematics education documents (Common Core State Standards Initiative [CCSSI] 2010; Department of Basic Education [DBE] 2011; National Council of Teachers of Mathematics [NCTM] 2000) and researchers in mathematics education (Komatsu 2010; Stylianides, The Notion of Proof in the Context of Elementary School Mathematics 2007) alike as vital in the learning of mathematics across all the grades, little is known about the level of communication patterns in classrooms of early career teachers of mathematics. The level of communication patterns is important to determine because it is a phenomenon that helps to determine the degree to which classroom mathematical practice is 'honest to mathematics as a discipline and honoring of students as mathematical learners' (Stylianides 2007: 3). The term 'intellectual-honesty principle' was coined by Stylianides (2007) to stress the importance of 
ensuring that classroom practice not only reflects the practice of mathematicians but also accords learners the dignity of learning mathematics rather than its mutated form characterised by the need to memorise unintelligible rules and procedures for passing tests and examinations. In other words, this principle raises awareness of the importance of respecting our learners by giving learners the 'real deal' rather than placing emphasis on procedural and conceptual knowledge aimed at passing tests and examinations. I concur with Komatsu (2010: 1) in his assertion that 'this principle is valuable for not only proofs in school mathematics but also all mathematical learning at all grades'.

Thus, this review focuses on previous literature on conjecturing in primary mathematics because at the core of doing and knowing mathematics is conjecturing (Stylianides \& Stylianides 2009). This need not be construed as an indictment on the focus on mastery of computational skills. Truth is, although the acquisition of procedural and conceptual knowledge is important and has garnered more attention than mathematical practices (e.g., conjecturing), besides potentially being harmful to learners' capabilities later in their mathematics education (Bieda, Ji, Drwencke \& Picard 2014), these approaches to learning mathematics may not expose the true beauty and nature of mathematics (Rumsey 2012). With this background in mind, this study has three aims. First, to explore the communicative patterns during classroom interaction mediated by an early career teacher. Second, to determine the classroom environment in which the interactions take pace. Third, to characterise the quality of these interactions by focusing specifically on determining the frequency of high interanimation of conjectures as compared to the total number of learners' conjectures. The research questions guiding this study are:

1. What are the communicative patterns in the classroom of a teacher?

2. What is the nature of this teacher's classroom learning environment?

3. How is the quality of these communicative patterns in the classroom?

By way of preview, the following findings were made:

1. The early career teacher's classroom was relatively interactive but authoritative. 
2. The classroom environment conform to reform initiatives in mathematics.

3. The quality of the communicative approach was low; most $(66 \%)$ of the interactions exhibited a low interanimation of ideas.

\section{Theoretical Framework}

I hold the view that mathematics classroom activities can understood when investigated from social perspectives because of the nature of the schooling system. Hence Vygotsky's theory of learning became an obvious choice. Vygotsky's (1978) sociocultural theory of learning frames the exploration of classroom interactions and served as a lens with to interpret results in this study. In terms of this theory, the society's contribution to the development and learning of a child is appreciated. In addition, this theory appreciates the interaction between the culture in a child's life and their development and learning. By culture here is meant 'shared motives, values, beliefs, identities, and interpretations or meanings of significant events that result from common experiences of members of collectives that are transmitted across generations' (House, Hanges, Javidan, Dorfman \& Gupta 2004: 15). According to Thompson (1992), beliefs relate to individual learner's views, conceptions and theories. In this study, a belief is a view, conception, theory that a person holds as true of mathematical principles based upon their own experiences, experiments, emotions or social influence. The central idea of this theory is that learning is predominately a social process rather than an isolated entity.

Vygotsky (1978) introduced the concepts of zone of proximal development (ZPD), scaffolding, and internalisation to challenge Piaget's theory relating to the relationship between development and learning, that learning should be matched with the child's level of biological development. This zone is the area of exploration for which the learner is cognitively prepared, but requires 'scaffolding' which is the help and social interaction provided by a teacher or in collaboration with more capable peers to fully develop. Vygotsky (1978) refers to the taking in of new knowledge observed in social contexts and mediated through language as internalisation. Alongside these Vygotskian perspectives we are reminded of the argument that constructing mathematical knowledge entails observation and conjecturing with mathematical objects.

This sociocultural perspective of children's development is suitable for 
this study on two counts. First, the foundation phase (Grades 1-3) mathematics Curriculum and Assessment Policy Statement (CAPS) defines mathematics as 'a human activity that helps learners to 'develop mental processes that enhance logical and critical thinking, accuracy and problem-solving that will contribute to decision-making' (Department of Basic Education [DBE] 2011: 8). Second, it is incumbent upon teachers to introduce and facilitate learners' enculturation into the mathematical practices. These two ideas taken together are consistent with Vygotsky's (1978) perspective that learning involves a passage from social contexts to individual understanding. In describing the relationship between classroom talk and learning, Turner, Dominguez, Maldonado, and Empson (2013: 203) assert that:

discussions afford opportunities for students to do such things as explain and justify solution strategies, pose questions, and articulate connections between mathematical ideas. In other words, they afford opportunities for students to take on agentive problemsolving roles and to participate in ways that can impact students' dispositions toward the subject and, over time, their sense of themselves as competent, agentive learners.

\section{Methods}

The interpretivist paradigm within a qualitative methodology underpinned this study. In particular, this study followed an interpretivist paradigm to gain an insider view (Creswell 2014) of the character of classroom interactions to answer the research questions on the communicative patterns that characterised the sequence of mathematics lessons of the early career teacher. Mortimer and Scott's (2003) provided an analytical framework for describing the nature of classroom interactions in the lessons delivered by the early career teacher and to come to a better understanding of the learners' experiences of mathematics lessons and thus increase the trustworthiness of the findings. Classrooms of early career teachers are interesting to study because they reveal much about the teacher's instructional practices which are likely to be challenged during the first few years of teaching as their teaching and learning ideals are pitted against the realities of actual classroom (Brown \& Borko 1992). In addition, early career teachers are more familiar with both content and instructional practices that the Curriculum and Assessment Policy Statement (CAPS) (Depart- 
ment of Basic Education [DBE] 2011) demands due to having recently graduated from teacher preparation programmes that emphasise these practices.

\section{Setting}

The research site is a large community school on the Eastern part of the Eastern Cape province of South Africa approximately $42 \mathrm{~km}$ from Lusikisiki with 350 learners on its roll, 18 teachers and 5 support staff. Given the low employment levels associated with South African village life, and as is the case with most learners in South Africa, the participating schools is a no-fee school. Nationally, of the $65 \%$ of learners attending no-fee schools, $82 \%$ of them are in the Eastern Cape compared to $41 \%$ and $45 \%$ such learners in the Western Cape and Gauteng, respectively (Statistics South Africa 2016). The extent of poverty in the Eastern Cape is shown by the level of support provided by the National Schools' Nutrition Programme (NSNP). This programme, introduced two decades ago by the South African government to ensure that children living in poverty-stricken households are not deprived of participating in the education system on the basis of lack of nutritional food. Thus, learners participated in the school feeding scheme that provided them with lunch during break periods. The mathematics period in the school was approximately forty minutes long, five days per week.

\section{Participants}

The sample of 48 learners will be relatively homogenous in terms of gender (27 female and 21 male), age ( $\bar{x}=10$ years), and socio-economic status. Learners in the intermediate phase are interesting to study because they are at the important crossroads in their mathematical education in that they are 'forming conclusions about their mathematical abilities, interest, and motivation that will influence how they approach mathematics in later years' (Protheroe 2007: 52).

\section{Procedure}

A focus group discussion protocol was designed and piloted with five participants from a separate class taught by the early career teacher who were not part of the sample whose results are reported in this study. Feedback from 
these learners helped to reword any unclear questions. The purpose of the study was explained to all three classes with emphasis placed on confidentiality and anonymity. At the focus group interview stage, as the moderator I eased participants into the discussion by serving them refreshment and engaging them in small talk like asking each one to introduce themselves, an activity you like to do in your spare time, and talk about their favourite sport (Dilshad \& Latif 2013). After this rapport-building phase, I shifted the conversation to their experiences of mathematics with the early career teacher after explaining to them the purpose of the interview, stating ground rules, telling them that there were no right or wrong answer, assuring them that nobody, not even the early career teacher, would know what they said in the discussion. Probing helped to steer the discussion towards discussions that tended to elicit perspectives that answered the research question. In concluding the interview, I asked the group to add if I missed something. To reciprocate the early career teacher's willingness to agree to provide access to her classroom, the scored observation protocol was discussed and handed over to him for reexamining her own teaching practices.

\section{Data Collection}

This study used multiple data collection methods. Initially, classroom interactions were observed for two weeks to obtain a rich understanding of the communication patterns that obtained in the classes of the early career teacher. Observation was chosen as one of the data collection technique because it allows for building of rapport and enables familiarity with the setting and is not affected by the limitations associated with self-report bias (McMillan \& Schumacher 2010). In an attempt not to overwhelm the early career teacher and remain focused on obtaining trustworthy results, I did not participate in the classroom activities. In addition to using an observational method, I adopted the Reform Teaching Observation Protocol (RTOP) which I personally filled out for each of the teacher's lessons. This protocol was designed by the Evaluation Facilitation Group (EFG) of the Arizona Collaborative for Excellence in the Preparation of Teachers (ACEPT) to measure 'reformed' teaching from primary school through to university mathematics and science. In addition, RTOP affirms the importance of specialised preparation, knowledge, and professional development for physics teachers (MacIsaac \& Falconer 2002). By reformed teaching is meant a classroom learning 
environment in which learners use data to justify their positions and learn from one another, and stress a problem solving approach, in concert with the mathematics reform efforts as embodied in reform documents (Sawada et al. 2002). The protocol contains twenty-five items, divided into five subscales (Lesson design and implementation, Propositional Knowledge, Procedural Knowledge, Student-teacher classroom interaction, Student-student classroom interaction) each of which features 5 items on a scale of $0-4$, for a maximum possible score of 100 points. Given that this protocol was used to conduct multiple observations, the trustworthiness of the findings was enhanced.

\section{Data Analysis}

The communicative approach focuses on the ways in which the early career teacher works with her learners to address the different ideas that emerge during the lesson (Mortimer \& Scott 2003). Drawing on the work of Bakhtin (1934) which underscores the dialogic nature of meaning making in the classroom, Mortimer and Scott (2003) developed a framework to describe how to the sociocultural theory can be used to study classroom practice, specifically interactions. The communicative approach - the focus of this study constitutes one of the five components of the framework, the other four being teaching purpose, content, patterns of discourse, and teacher interventions. This aspect of the framework is not only confined to whether or not the teacher interacts with learners but also whether the teacher takes account of learners' diverse conjectures that emerge during the lesson (Mortimer \& Scott 2003). They identified four fundamental classes of communicative approach generated from categorising the talk between teacher and learners along two continuous dimensions: a continuum between dialogic and authoritative talk on the one hand and a continuum between interactive and non-interactive talk on the other hand.

The characterisation of the quality of communication patterns in the mathematics classrooms of an early career teacher took place through Mortimer and Scott's (2003) model. The model comprise five linked aspects to analyse the role of the teacher in supporting learners in meaning making in the classroom: teaching purpose; content; communicative approach; patterns of discourse, and; teacher interventions. For this study, the communicative approach aspect of the framework was used to analyse the early career teacher's lessons. Episodes of classroom interactions were coded according to 
these components of the communicative approach: either interactive/dialogic, non-interactive/ dialogic, non-interactive/ dialogic, or non-interactive/ authoritative. These components of the model are described in Table 1, below.

\section{Table 1. The communicative approach analytical tool (Mortimer \& Scott 2003)}

\begin{tabular}{|c|c|c|}
\hline & INTERACTIVE & NON-INTERACTIVE \\
\hline DIALOGIC & Interactive/ & Non-interactive/ \\
\hline & Dialogic $^{\mathrm{a}}$ & Dialogic $^{c}$ \\
\hline AUTHORITATIVE & $\begin{array}{l}\text { Interactive/ } \\
\text { Authoritative }^{\mathrm{b}}\end{array}$ & $\begin{array}{l}\text { Non-interactive/ } \\
\text { Authoritative }^{\mathrm{d}}\end{array}$ \\
\hline
\end{tabular}

${ }^{a} / \mathrm{D}$ Interactive/Dialogic: teacher encourages learners to put forward their ideas including those that are quite different from the mathematical view.

${ }^{b}$ NI/D Non-interactive/Dialogic: teacher considers learners' possible misconceptions without inviting any input from learners.

'I/A Interactive/Authoritative: teacher uses a question-and-answer session to convey and consolidate the mathematical view though more than one view may be heard - alternative views are discounted. The teacher's sole aim is to focus on the single view, the mathematics view.

${ }^{d}$ NI/A Non-interactive/Authoritative: as in delivering of a lecture, the teacher presents the mathematics view only in a monologue. A 'closed' teaching situation in that new voices are not entertained by the teacher.

However, although classroom interactions research focuses on examining behaviours and strategies used by teachers and learners and how these features correlated with learner performance (Rex \& Green 2008), in this study, the focus is limited only to the early career teacher talk meant to facilitate learners' mathematical knowledge construction through elicitation of learners' ideas within the 'official classroom air time' (Cazden, 2001: 54). As a consequence of this focus, excerpts featuring teacher talk which show patterns of interactions in the communicative approach were identified for analysis. Thus, the analysis focused on the quality of communicative approach by exploring the teacher helped her learners to build new knowledge (new to learners, at 
least) by making connections between what they know and what they are supposed to learn. In this sense, other than merely adopting the 'What is ... ?' questioning line, the teacher needed to probe learners' ideas, by including questions such as 'Why makes you think so?', 'How?', 'What if ...?' or 'Give an example ...', 'Do you agree with ...', 'How do you know that?', 'Can you elaborate on why ...', and so on (Chin 2006; Mortimer \& Scott 2003).

However, while exploration of classroom interactions is important, more valuable is to determine the quality of these interactions to see whether they indeed experience mathematics that is honest to the discipline and the teacher's practices honours them as mathematical learners. To do this, I investigated the interactive/dialogic (I/D) communicative approach in which there are two different levels of interanimation (exploration) of learners' conjectures (see, Table 2), as pointed out by Scott, Mortimer, and Aguiar (2006). They point out that exploration of learners' conjectures about mathematical ideas takes place at low interanimation in situations where although a teacher elicits learners' conjectures about the ideas in topics under discussion, but neither the teacher nor the learners probe the conjectures about mathematical ideas or make connections between the various conjectures. In contrast, high interanimation of learners' conjectures refers to the collection and probing, comparing and contrasting of conjectures about mathematical ideas with a view to making connections between what is known and new concepts.

\section{Table 2. Dialogic discourse and interanimation of ideas (Scott, Mortimer \& Aguiar 2006)}

$\begin{array}{cc}\text { Dialogic } & \text { LOW level of } \\ \text { discourse } & \begin{array}{c}\text { interanimation of } \\ \text { conjectures about } \\ \text { mathematical ideas. }\end{array} \\ & \text { HIGH level of } \\ \text { interanimation of } \\ \text { conjectures about } \\ \text { mathematical ideas }\end{array}$

Different ideas are made available on the social plane.

Different ideas are explored and worked on by comparing, contrasting, developing. 
In Table 3, I present the three topics from the teaching of the Grade 4 mathematics lessons. The three lessons were on varied topics, as illustrated in Table 2.

Table 3: Lessons recorded, transcribed and analysed

\begin{tabular}{llcc}
\hline Transcript & Topic & Grade & $\begin{array}{c}\text { Length of } \\
\text { period }\end{array}$ \\
\hline A & Tallying & 4 & 40 minutes \\
B & Pictographs & & \\
C & Bar Graphs & & \\
\hline
\end{tabular}

The data in the RTOP was analysed according to three themes: traditional lecture; active lecture; and active learning. The classroom interactions were judged according to the following score ranges: traditional, 0-29; active, 3049; and active learning, 50 and above. Noteworthy is that a score of 100 and above indicates a reformed, learner-driven classroom environment consistent with reform efforts.

\section{Findings}

Using excerpts from an episode, I counted the number of instances in which the communicative approaches occurred in six (see, Appendices A - F) of the ten lessons observed. The purpose of this exercise was to tally, then compare and contrast the communicative approaches in order to establish findings for the investigation. Table 4 below is presented to illustrate the prevalence of the interactive/authoritative patterns in the excerpts. Specifically, 66\% of the interactions were primarily interactive/authoritative. As can be seen in the table, none of the learners' responses were probed and made available to the whole class to interrogate; they were neither interactive/dialogic nor noninteractive/ dialogic.

First, Figure 3 shows an example of an interactive/authoritative segment of the interactions in which the teacher's focus is on telling the mathematics story without inviting various learners' ideas to be explored on the social plane; she does not treat learners' responses as conjectures. Learner 1 's response of 100 in line 6 is not put to the class for exploration. 
Teacher: What was our number A. number A. Hands up! Number A. We were dividing 165 by 5 . Isn't it?

Learners (Chorus): Yes, mam

Teacher: 165 divided by 5 . Ok, let us do the solution. What do we do first?

... [Chorus answers] Hands up! ... Yes

\section{Learner 1: 100}

Teacher: Yeah, 100, continue. 100 ... [Answer from learner not forthcoming]

Masimncediseni (Let us all help him). Yes

Table 4. Frequency of communicative patterns

\begin{tabular}{lcccc}
\hline $\begin{array}{l}\text { Lesson } \\
\text { topic }\end{array}$ & $\begin{array}{c}\text { INTERACTIVE } \\
\text { Interactive / } \\
\text { Dialogic }\end{array}$ & $\begin{array}{c}\text { Non- } \\
\text { interactive / } \\
\text { Dialogic }\end{array}$ & $\begin{array}{c}\text { NON-INTERACTIVE } \\
\text { Interactive / } \\
\text { Authoritative }\end{array}$ & $\begin{array}{c}\text { Non- } \\
\text { interactive / } \\
\text { Authoritativ } \\
\text { e }\end{array}$ \\
\hline Tallying & 0 & 0 & 21 & 6 \\
Pictographs & 0 & 0 & 13 & 10 \\
Bar Graphs & 0 & 0 & 17 & 10 \\
\hline Total & $\mathbf{0}$ & $\mathbf{0}$ & $\mathbf{5 1}$ & $\mathbf{2 6}$ \\
\hline
\end{tabular}

The next excerpt (Figure 4) provides some more evidence for the case of an interactive/ authoritative pattern of communication. In lines 9-16, the teacher confirms Learner 2's response by repeating it herself to the class. However, she does not pass this response for checking of its validity by the whole classroom.

Learner 2: 100 divided by 5

Teacher: 100 divided by 5 [teacher repeats learner's answer]. Next?

Learner 3: 60

Teacher: 60 divided by ... 5? Yes ... yeah ...

Learner 2: What is 100 divided by 5 ? ... Yes, Alipheli?

Learner: 20

Teacher: 5 divided by 5

Learner 1: 1 
In the following excerpt, the teacher only entertains responses that are consistent with the canonical ideas of mathematics. In lines 17-23, Learner 4's response is judged by the teacher as incorrect, hence she tries to show him that he needs to reconsider his answer.

Teacher: 5 divided by 5 [teacher repeats learner's answer]. Ok, let us get the answers. 60 divided by 5 ? ... Akpani?

\section{Learner 4: 300}

Teacher: Hhhe

Learner 4: 300 [Repeating her earlier answer]

Teacher: When you say 60 divide by 5 we get 300 ? How come it's 300 where we divide 60 not 100 . Let us count in 5's

The nature of the excerpts indicates that low interanimation of ideas was prevalent. That is, although learners provided different responses as their answers to the teacher's questions, these responses were not contrasted and compared to test their veracity. An overall RTOP score of 43 which reflected that there was relatively some degree of active learner participation in the lessons was consistent with the findings obtained in classroom observations as are shown in the excerpts. In the next section I examine the data to determine points of convergence between the findings in this study and the existing literature.

\section{Discussion}

This study investigated classroom talk in the mathematics lessons of an early career teacher in a primary school with a focus on the teacher-learner interactions. The results of the study show that on the whole, the quality of these interactions is low. In fact, despite the teacher's attempts to interact with her learners, these interactions were characterised by episodes in which only the ideas deemed consistent with the mathematical view were tolerated. Thus, interactions in which learners' ideas were made available on the social plane for the purpose of probing conjectures were far and few in between. This result is consistent with that of Arends, Winnaar, and Mosimege (2017) who found that the opportunities for the learners to make conjectures through the discussion technique was very small. According to Mercer and Sams' (2006) and Sfard's (2007) findings in Grade 5 classrooms, the low interanimation of 
ideas is indicative of learners' inadequate prior content knowledge necessary to engage in meaningful classroom talk.

The observations of the lessons provided evidence that the early career teacher struggles with orchestrating interactions embedded in sense making. Although in all three lessons observed, the teacher was well-prepared for the lessons and appeared very comfortable from the mathematical content point of view, a number of opportunities arose for him to probe learners' responses for deeper learning, reasoning, refining ideas on the social plane. However, very little attempts were made by the teacher to seize these moments to develop the mathematical story.

Given the low participation of girl learners in mathematics in general and in mathematics-related careers in particular, policy interventions intended to improve girls' and women's participation in mathematics discipline over the past two decades, future research endeavours can shed light into how participation and the quality of classroom talk are distributed across gender in developing countries such as South Africa. In the construction of mathematical knowledge, the Specific Aims of CAPS and the nature of school mathematics in general reveal an interesting contradiction. On one hand, the CAPS document advocates for assessment approaches that encourage investigations of mathematical objects through conjecturing. Yet, on the other hand, the education system pressures its teachers to cover prescribed content within a specified time period to prepare learners for tests and examinations.

\section{Conclusion}

The purpose of this study was to understand the instructional practices in which an early career teacher engages to add knowledge to the understanding of the behaviour and strategies in classroom interactions that are associated with meaningful learning of mathematics in the primary schools. I have built a rationale for this study by describing citing germane work, stating the hypothesis and considering propositions of previous studies, defining terms, and clarifying limitations (Merriam \& Simpson 2000). The four categories of the communicative approach obtained from the combination of two dimensions along which the types of interactions in lessons of the early career teacher functions, provided a framework for analysing these interactions.

The finding that the early career teacher was found wanting in respect of scaffolding his learners in the meaningful learning of mathematics, in this 
particular research, suggests that the teacher requires assistance in the orchestration of classroom interaction that help learners develop views that reflect the practices in the mathematics discipline. Thus, the implication resulting from this recommendation is that teacher preparation programmes need to redefine classroom interactions to equip preservice teachers with the necessary skills to conduct classroom talk in ways that resemble the practices of mathematicians, especially conjecturing work. Additionally, many questions relating to the effect of factors such as class size and pressure to adhere to the delivery of the content as dictated to by the curriculum remain unanswered and may be the subject of further research. Whereas this study is limited in that it followed three lessons of a single early career teacher only, restraining the size of the sample enabled a deeper analysis of the mathematical experiences of these 48 learners.

One particular limitation of this study is that the findings were based on only three observations of a single classroom of a single early career teacher due to constraints in resources (time and funding). The decision to use a case study approach was based on Merriam and Tisdell (2016), who reason that the general can be found in the particular in that lessons learnt in one situation can be transferred or generalised to subsequent similar situations if 'thick' descriptions are used as a strategy to enable transferability of the results of a study to another setting. By 'thick' description is meant a 'detailed description of the setting, participants, and the findings with adequate evidence presented in the form of quotes from participants' interviews, field notes, and documents (Merriam \& Tisdell 2016: 257). Another limitation is that a few of the learners were silent during the interactions and thus their ideas remained unavailable for subsequent analysis.

\section{References}

Aaron, W.R. \& P.G. Herbst 2015. Teachers' Perceptions of Students' Mathematical Work while Making Conjectures: An Examination of Teacher Discussions of an Animated Geometry Classroom Scenario. International Journal of STEM Education 2,10: 1 - 13.

https://doi.org/10.1186/s40594-015-0021-0

Abrahamson, D. \& R. Sánchez-García 2016. Learning is Moving in New Ways: The Ecological Dynamics of Mathematics Education. Journal of 
the Learning Sciences 25,2: 203 - 239.

https://doi.org/10.1080/10508406.2016.1143370

Arends, F., L. Winnaar \& M. Mosimege 2017. Teacher Classroom Practices and Mathematics Performance in South African Schools: A Reflection on TIMSS 2011. South African Journal of Education 37,3: 1 - 11. Available at: https://doi.org/10.15700/saje.v37n3a1362

Bakhtin, M.M. [1934] 1981. Discourse in the Novel. In Holquist, M. (ed.): The Dialogic Imagination. Emerson, C. \& M. Holquist (trans.). Austin: University of Texas Press.

Balacheff, N. 1988. Aspects of Proof in Pupils' Practice of School Mathematics. In Pimm, D. (ed.): Mathematics, Teachers, and Children. London: Hodder \& Stoughton.

Ball, D.L., J. Lewis \& M.H. Thames 2008. Making Mathematics Work in School. In Schoenfeld, A.H. \& N. Pateman (eds.): A Study of Teaching: Multiple Lenses, Multiple Views. Reston, VA: National Council of Teachers of Mathematics.

Bay-Williams, J.M., M. McGatha, M.B. Kobett \& J.A. Wray 2013. Mathematics Coaching: Resources and Tools for Coaches and Leaders, $K-12$. Boston: Pearson.

Bergqvist, T. 2005. How Students Verify Conjectures: Teachers' Expectations. Journal of Mathematics Teacher Education 8,2: 171 - 191.

https://doi.org/10.1007/s10857-005-4797-6

Bieda, K.N., C. Ji, J. Drwencke \& A. Picard 2014. Reasoning-and-proving Opportunities in Elementary Mathematics Textbooks. International Journal of Educational Research 64: 71 - 80.

https://doi.org/10.1016/j.ijer.2013.06.005

Callejo, M.L. \& A. Vila 2009. Approach to Mathematical Problem Solving and Students' Belief Systems: Two Case Studies. Educational Studies in Mathematics 72,1: 111 - 126.

https://doi.org/10.1007/s10649-009-9195-z

Cañadas, M.C., J. Deulofeu, L. Figueiras, D. Reid, \& O. Yevdokimov 2007. The Conjecturing Process: Perspectives in Theory and Implications in Practice. Journal of Teaching and Learning 5,1: 55 - 72.

https://doi.org/10.22329/jtl.v5i1.82

Cazden, C.B. 2001. The Language of Teaching and Learning. Portsmouth, NH: Heinemann.

Chin, C. 2006. Classroom Interaction in Science: Teacher Questioning and 
Feedback to Students' Responses. International Journal of Science Education 28,11: 1315 - 1346.

https://doi.org/10.1080/09500690600621100

Chinnappan, M. 2005. Connections, Conjectures and Problem Solving in Primary Mathematics: The Role of Magic Squares. Reflections 30,1: 33 34.

Cobb, P., T. Wood \& E. Yackel 1993. Discourse, Mathematical Thinking, and Classroom Practice. In Forman, E.A., N. Minick \& C.A. Stone (eds.): Contexts for learning: Sociocultural Dynamics in Children's Development. New York, NY: Oxford University Press.

Common Core State Standards Initiative [CCSSI] 2010. Common Core State Standards for Mathematics (CCSSM). Washington, DC: National Governors Association Center for Best Practices and Council of Chief State School Officers. Available at: http://www.corestandards.org/wpcontent/uploads/Math_Standards.pdf (Accessed on 24 February 2018.)

Creswell, J.W. 2014. Research Design: Qualitative, Quantitative, and Mixed Methods Approaches. $4^{\text {th }}$ Edition. Thousand Oakes, CA: Sage.

Department of Basic Education [DBE] 2011. Curriculum and Assessment Policy Statement: Mathematics (Grades 1-3). Pretoria: Department of Basic Education.

Dilshad, R.M. \& M.I. Latif 2013. Focus Group Interview as a Tool for Qualitative Research: An Analysis. Pakistan Journal of Social Sciences 33,1: 191 - 198.

House, R.J., P.J. Hanges, M. Javidan, P.W. Dorfman \& V. Gupta (eds.). 2004. Culture, Leadership, and Organizations: The GLOBE Study of 62 Societies. Thousand Oaks: Sage.

Jones, K. \& T. Fujita 2013. Interpretations of National Curricula: The Case of Geometry in Textbooks from England and Japan. ZDM: The International Journal on Mathematics Education 45,5: 671 - 683.

https://doi.org/10.1007/s11858-013-0515-5

Komatsu, K. 2010. Counter-examples for Refinement of Conjectures and Proofs in Primary School Mathematics. Journal of Mathematical Behavior 29,1: 1 - 10.

https://doi.org/10.1016/j.jmathb.2010.01.003

Lampert, M. 1990. When the Problem is not the Question and the Solution is not the Answer: Mathematical Knowing and Teaching. American Educational Research Journal 27,1: 26 - 63. 


\section{https://doi.org/10.3102/00028312027001029}

Lee, K.-H. \& B. Sriraman 2011. Conjecturing via Reconceived Classical Analogy. Educational Studies in Mathematics 76,2: 123 - 140. https://doi.org/10.1007/s10649-010-9274-1

MacIsaac, D. \& K. Falconer 2002. Reforming Physics Instruction via RTOP.

The Physics Teacher 40,8: 479 - 485.

https://doi.org/10.1119/1.1526620

Manouchehri, A. \& D. St. John 2006. From Classroom Discussions to Group Discourse. Mathematics Teacher 99,8: 544 - 551.

McMillan, J.H. \& S. Schumacher 2010. Research in Education: Evidencebased Inquiry. $7^{\text {th }}$ Edition. Upper Saddle River, New Jersey: Pearson Education, Inc.

Mehan, H. 1979. Learning Lessons: Social Organization in the Classroom. Cambridge, MA: Harvard University Press.

Mercer, N. \& S. Sams 2006. Teaching Children How to Use Language to Solve Maths Problems. Language and Education 20,6: 507 - 528. https://doi.org/10.2167/le678.0

Merriam, S.B. \& E.L. Simpson 2000. A Guide to Research for Educators and Trainers of Adults. Malabar, FL: Krieger.

Merriam, S.B. \& E.J. Tisdell 2016. Qualitative Research: A Guide to Design and Implementation. $4^{\text {th }}$ Edition. San Francisco, CA: Jossey-Bass.

Mortimer, E.F. \& P.H. Scott 2003. Meaning Making in Secondary Science Classrooms. Berkshire: McGraw-Hill International.

Mueller, M. \& C. Maher 2009. Learning to Reason in an Informal Math Afterschool Program. Mathematics Education Research Journal 21,3: 7-35. https://doi.org/10.1007/BF03217551

National Center for Educational Achievement [NCEA] 2009. Core Practices in Math and Science: An Investigation of Consistently Higher Performing Schools in Five States. Austin, TX: National Center for Educational Achievement.

National Council of Teachers of Mathematics [NCTM] 1991. Principles and Standards for School Mathematics. Reston, VA: NCTM.

National Council of Teachers of Mathematics [NCTM] 2000. Principles and Standards for School Mathematics. Reston, VA: NCTM.

Organisation for Economic Cooperation and Development [OECD] 2006. OECD Science, Technology and Industry Outlook Highlights. OECD. Available at: 
http://www.oecd.org/dataoecd/39/19/37685541.pdf

(Accessed on 12 June 2018.)

Protheroe, N. 2007. What does Good Math Instruction Look Like? Principal 87,1: 51 - 54.

Raue, K. \& L. Gray 2015. Career paths of beginning public school teachers: Results from the first through fifth waves of the 2007-2008 beginning teacher longitudinal study (NCES 2015-196). Washington, DC: National Center for Education Statistics. Available at: http://nces.ed.gov/pubsearch (Accessed on 18 August 2018.)

Reid, D.A. 2002. Conjectures and Refutations in Grade 5 Mathematics. Journal for Research in Mathematics Education 33,1: 5 - 29. https://doi.org/10.2307/749867

Reid, D.A. 2011. Understanding Proof and Transforming Teaching. In Wiest, L.R. \& T. Lamberg (ed.): Proceedings of the $33^{\text {rd }}$ Annual Meeting of the North American Chapter of the International Group for the Psychology of Mathematics Education. Reno: University of Nevada. Available at: https://www.pmena.org/pmenaproceedings/PMENA\%2033\%202011\%2 OProceedings.pdf

Rex, L.A. \& J.L. Green 2008. Classroom Discourse and Interaction: Reading across the Traditions. In Spolsky, B. \& F. Hult (eds.): Handbook of Educational Linguistics. Oxford: Blackwell.

https://doi.org/10.1002/9780470694138.ch40

Rumsey, C.W. 2012. Advancing Fourth-grade Students' Understanding of Arithmetic Properties with Instruction that Promotes Mathematical Argumentation. Unpublished doctoral dissertation. Illinois State University, Normal, IL.

Rumsey, C.W. 2013. A Model to Interpret Elementary-school Students' Mathematical Arguments. In Lindmeier, A.M. \& A. Heinze (eds.): Proceedings of the $37^{\text {th }}$ Conference of the International Group for the Psychology of Mathematics Education, 28 July - 2 August 2013. Kiel, Germany: University of Kiel.

Rumsey, C.W. \& C.W. Langrall 2016. Promoting Mathematical Argumentation. Teaching Children Mathematics 22,7: 413 - 419.

https://doi.org/10.5951/teacchilmath.22.7.0412

Sawada, D., M.D. Piburn, E. Judson, J. Turley, K. Falconer, R. Benford \& I. Bloom 2002. Measuring Reform Practices in Science and Mathematics Classrooms: The Reformed Teaching Observation Protocol. School 
Science and Mathematics 102,6: 245 - 253.

https://doi.org/10.1111/j.1949-8594.2002.tb17883.x

Schuck, S., P. Aubusson, J. Buchanan, M. Varadharajan \& P.F. Burke 2018.

The Experiences of Early Career Teachers: New Initiatives and Old

Problems. Professional Development in Education 44,2: 209 - 221. https://doi.org/10.1080/19415257.2016.1274268

Schultz, K. 2009. Rethinking Classroom Participation: Listening to Silent Voices. New York, NY: Teachers College Press.

Scott, P.H., E.F. Mortimer \& O.G. Aguiar 2006. The Tension between Authoritative and Dialogic Discourse: A Fundamental Characteristic of Meaning Making Interactions in High School Science Lessons. Science Education 90,4: 605 - 631.

https://doi.org/10.1002/sce.20131

Sfard, A. 2007. When the Rules of Discourse Change, but Nobody Tells you:

Making Sense of Mathematics Learning from a Commognitive

Standpoint. Journal of the Learning Sciences 16,4: 565 - 613. https://doi.org/10.1080/10508400701525253

Statistics South Africa 2016. Community Survey 2016/ Statistical Release P0301. Pretoria: Statistics South Africa.

Stylianides, A.J. 2007. The Notion of Proof in the Context of Elementary

School Mathematics. Educational Studies in Mathematics 65,1: 1 - 20.

https://doi.org/10.1007/s10649-006-9038-0

Stylianides, A.J. \& G.J. Stylianides 2009. Proof Constructions and Evaluations. Educational Studies in Mathematics 72: 237 253https://doi.org/10.1007/s10649-009-9191-3

Thompson, A.G. 1992. Teachers' Beliefs and Conceptions: A Synthesis of the Research. In Grouws, D. (ed.): Handbook of Research on Mathematics Teaching and Learning: A Project of the National Council of Teachers of Mathematics. New York: Macmillan.

Thurston, W.P. 1995. On Proof and Progress in Mathematics. For the Learning of Mathematics 15,1: 29 - 37.

Umalusi 2014. What's in the CAPS Package? A Comparative Study of the National Curriculum Statement (NCS) and the Curriculum and Assessment Policy Statement (CAPS). Pretoria: Umalusi Council of Quality Assurance in General and Further Education and Training.

Vygotsky, L.S. 1978. Mind in Society: The Development of Higher Psychological Processes. Cambridge, MA: Harvard University Press. 
Yevdokimov, O. 2003. Intuitive Proofs as a Tool for Development of Students' Creative Abilities while Solving and Proving: Short Oral Presentation. In Pateman, N.A., B.J. Dougherty \& J. T. Zilliox (ed.): Proceedings of the Twenty-seventh Annual Conference of the International Group for the Psychology of Mathematics Education, 13 - 18 July 2003. University of Hawai'i, Honolulu.

Benjamin Shongwe Department of Mathematics Education School of Education University of KwaZulu-Natal shongweb@ukzn.ac.za 